\title{
LIBROS NUEVOS
}

\section{Reseñas}




\section{GUARDIOLA ORTIZ, DAGMAR}

\section{EL TRABAJO SOCIAL EN EL CARIBE HISPANO ANTILLANO \\ VOL. I}

Roberto Cassá ${ }^{l}$

Como no soy especialista en la disciplina del Trabajo social, quisiera centrar mis comentarios en el primer tomo de la obra, producto de la labor colectiva de investigadores de las tres islas del Caribe hispánico. Tengo que subrayar este objetivo desde el momento en que el primer tomo está concebido como una aproximación comparativa a los procesos históricos de las tres islas con el fin preciso de contextualizar el análisis de la trayectoria del trabajo social en la región que desemboque en la enunciación de propuestas que respondan a la experiencia del pasado y a la situación del presente. Mientras el contexto histórico está elaborado por cinco autores y dos colaboradores, además de la doctora Guardiola, el segundo es de la autoría exclusiva de ella. Lamento no tener la competencia para referirme a las reflexiones especializadas de la doctora Guardiola, aunque sus textos del tomo I, sobre todo el capítulo I de Introducción y el VI de Epílogo, relacionan las elaboraciones acerca del contexto socio-histórico con los objetivos especializados relativos al trabajo social.

La doctora Guardiola Ortiz se propone con esta investigación colectiva sentar las bases para una reflexión que permita un relanzamiento productivo de la acción del trabajo social en los tres países. La conceptualización de tal tipo de propuesta, considera, se debe hacer sobre bases históricas, lo que remite a la evaluación de los procesos que puedan tener conexión con la práctica del trabajo social.

\footnotetext{
' Director Archivo General de la Nación (República Dominicana).
} 
Me parece que en la obra se pone énfasis en una dialéctica de comunidad y diferencia. Con ayuda de ella se plantea la interrogante de hasta qué punto se pueden formular propuestas comunes de acción futura a la vista de la diversidad de procesos históricos entre los tres países. A pesar de esa variedad, se concluye en identificar problemas comunes en el presente. A juicio de la doctora Guardiola, esos problemas se sustentan en un proceso histórico común, que ha continuado a pesar de los hitos de trayectorias particulares que se inician a fines del siglo XVIII y que culminan tal vez con la Revolución cubana.

La aproximación que se produce acerca de estos problemas está inspirada en una perspectiva crítica que revaloriza la pertinencia de continuidad del trabajo social y sugiere la exigencia de que responda a los restos inéditos presentes en nuestra sociedades. Se puede leer en el texto de la doctora Guardiola la premisa del fracaso de los sistemas políticos en resolver los conflictos sociales del presente. A pesar de la diversidad que implican situaciones tan variadas como el colonialismo en Puerto Rico, la dependencia de República Dominicana y el sistema de tipo soviético de Cuba, aprecia la perpetuación de algunos males consuetudinarios y la aparición de otros. Me llama la atención sobre todo la perspectiva crítica que presenta en el sentido de que algunos de estos problemas están determinados por las fallas de los procesos de industrialización del siglo $\mathrm{XX}$, los cuales a su vez han estado vinculados con factores sociohistóricos comunes de larga duración y con circunstancias en el entorno internacional también comunes, en particular la gravitación de Estados Unidos.

Con el trazado de un examen del proceso histórico de los tres países, la doctora Guardiola tiene un fin muy preciso, como está en el centro de su propuesta metodológica. Desde luego, tiene intrínsecamente esa virtud. $Y$ tal vez por ella se ha producido una magnífica exposición de un conjunto de especialistas acerca de variopintos procesos históricos del Caribe hispánico en su conjunto y de cada uno de sus tres países por separado. A mi juicio, hasta donde conozco la literatura histórica de nuestras islas, tal tratamiento me ha resultado novedoso 
para no decir que inédito. Debe celebrarse como un acta de fundación de lo que está llamado a ser un estilo de trabajo intelectual en variadas disciplinas. La identificación comparativa de un campo de problemas comunes permitirá abordar los problemas del presente con mayor profundidad, un trasfondo histórico adecuado, rigor teórico y metodológico y sentido político concordante con la búsqueda de bienestar para nuestros pueblos.

Más allá de la convocatoria a tal estilo, esta obra adelanta fructíferos análisis cuyo conocimiento permitirá a puertorriqueños, dominicanos y cubanos conocernos mejor y estar en condiciones de abordar tareas comunes no obstante la diversidad de condiciones políticas y de peculiaridades de los procesos de desarrollo económico y cultural. La obra debe constituir un insumo para todos los especialistas imbuidos del propósito de sustentar propuestas en dimensiones históricas comparativas. Para los historiadores, en particular, se abren senderos de ánálisis comparativos que deberán tener por resultado síntesis que pongan de relieve las estructuras comunes y consiguientemente permitan profundizar en la dialéctica de comunidad y diferencia. Entiendo que tal abordaje, como lo efectúan la doctora Guardiola y los demás autores del tomo I, redundará en la revitalización de las utopías nacionales y en la culminación de ellas, el Antillanismo, tras cuyas materializaciones se dieron cita los movimientos más avanzados del pasado y los próceres que los lideraron. 